\title{
INVESTIGATIONS ON THE RELATIONSHIP BETWEEN POROSITY AND STRENGTH OF ADMIXTURES MODIFIED HIGH PERFORMANCE SELF-COMPACTING CONCRETE
}

\author{
Beata ŁAŹNIEWSKA-PIEKARCZYK \\ Faculty of Civil Engineering, Silesian Technical University, Akademicka 5 Str., 44-100 Gliwice, Poland
}

Received 28 Jan 2013; accepted 12 Jun 2013

\begin{abstract}
The influence of a type of new generation: superplasticizer (SP), anti-foaming admixture (AFA) and viscosity modifying admixture (VMA) on the air-content, workability of high performance self-compacting concrete (HPSCC) is analyzed in the paper. The purpose of this study was to examine the influence of type of the admixtures on porosity of HPSCC in the aspect of the compressive strength. The research results indicated that type of admixtures and its combinations result in different strengths of HPSCC, regardless of the total porosity characteristics of HPSCC.
\end{abstract}

Keywords: High Performance Self-compacting Concrete (HPSCC), Superplasticizer (SP), Anti-foaming Admixture (AFA), Viscosity Modifying Admixture (VMA), porosity, compressive strength.

\section{Introduction}

Self-compacting concrete is a concrete that is able to flow and consolidate under its own weight, completely fill the formwork even in the presence of dense reinforcement, whilst maintaining homogeneity and without the need for any additional compaction.

Superplasticizers (high-range water reducers) may increase or decrease the air content of a concrete mixture based on the admixture's chemical formulation and the slump of the concrete (Gołaszewski 2012; Ponikiewski 2012; Ponikiewski, Gołaszewski 2012). Naphthalene-based superplasticizers tend to increase the air content while melamine based materials may decrease or have little effect on air content. The normal air loss in flowing concrete during mixing and transport is about 2 to 4 percentage points (Whiting, Dziedzic 1992). The publication (MacInnis, Racic 1986) indicates that the superplasticizer causes reduction in total air-void surface areas and increases in air-void spacing factors. However, research results (Szwabowski, Łaźniewska-Piekarczyk 2008) indicated that certain superplasticizers (SP) of new generation produce an excessive air-entrainment remaining in the volume of the fresh mix and concrete, although the mix meets commonly accepted criteria of technical tests according to (EN 12350-8:2010) (2010). Moreover, most viscosity agents entrain a lot of air.

The volume of air in concrete has a direct, inverse impact on strength. Since the use of airentrainment in high-strength concrete reducers the compressive strength by about 5 percent or about $3.5 \mathrm{MPa}$ for each 1 percent increase in air content, it is desirable to minimalize the air content in order to achieve the strength. Although air entrainment often necessitates an increased amount of cement for a given strength, the increased cement content alone may not overcome the full loss in attain able strength because the gain per pound of cement added - that is, the cement efficiency - will progressively decline.

Some type of superplasticizers produce entrapped air voids, which are significantly larger than entrained voids (Szwabowski, Łaźniewska-Piekarczyk 2009; Gorzelańczyk, Hoła 2011; Gorzelańczyk 2012). As a result, the presence of larger entrapped voids increase the air content without offering any significant protection against scaling due to freezing in the presence of de-icing salts.

Too high volume of air has been overcome using an anti-foaming agent (AFA) (Łaźniewska-Piekarczyk 2009; Łaźniewska-Piekarczyk, Szwabowski 2012b). The components and their proportions used in the anti-foaming admixtures, as in SP, are known only to the producers. These ingredients could be mineral oils, silicone oils, organic modified silicones, hydrophobic constant molecules (silica, waxes, higher fatty acids soaps, alcohols and fatty acids), emulsifiers, polyalcohol or alcohol derivatives of organic compounds. The mechanism of anti-foaming admixture functioning is explained in publication (Łaźniewska-Piekarczyk 2010). These research

Corresponding author: Beata Łaźniewska-Piekarczyk

E-mail: beata.lazniewska@polsl.pl 
results proved that the self-compacting mortar containing AFA, despite of considerable fluidity, does not undergo segregation, different than in the case of mortars with no AFA with similar degree of fluidity (produced by higher amount of SP). Moreover, test results prove that mortars with AFA keep initial consistency for longer time in comparison with mortar with SP only. Moreover, the tests results (Łaźniewska-Piekarczyk, Szwabowski 2012a, 2012 b) prove that the time of anti-foaming admixture introduction is not essential for the effectiveness of decreasing the air-entrainment of the fresh self-compacting concrete. The application of anti-foaming admixtures may be used in order to prevent the excessive air-entrainment of mix (introducing anti-foaming admixture with air-entrained SP) or decrease existing air content (produced by airentrained SP) in fresh mix.

In case of too high level of mix consistency, which encourages the segregation of the mix, VMA should be used. VMA can be used to enhance the resistance to segregation and bleeding (Khayat 1998; Lachemi et al. 2003, 2004b; Guidelines ... 2006; Łaźniewska-Piekarczyk 2011a). When the total amount of fine particles is limited to $400 \mathrm{~kg} / \mathrm{m}^{3}$, SCC cannot be developed without any viscosity agent: its flow is very good but it presents high segregation (Rols et al. 1999). VMAs are high molecular weight, water soluble organic polymers that are used to stabilize the rheological properties and consistency of SCC. The mixtures with SP are very sensitive to small changes in the $\mathrm{w} / \mathrm{b}$ increasing the probability of segregation and bleeding. This is often observed in the production SCC (Sari et al. 1999). The research results in publication show that SCC with slump flow value $>700$ mm might segregate (Nagataki, Fujiwara 1995). The viscosity of a SCC mixture is controlled through the use VMA (Khayat, Guizani 1997; Lowke et al. 2003; Guidelines ... 2006; Prakash, Santhanam 2006). They essentially increase viscosity and thus thicken the mix to prevent segregation. This viscosity buildup comes from the association and entanglement of polymer chains of the VMA at a low shear rate, which further inhibits flow and increases viscosity. At the same time, added VMA causes a shear thinning behavior, decreasing viscosity, when there is an increase in shear rate. There are various types of VMAs, most of which are composed of either polymer or cellulose-based materials, which "grab and hold" water. The most important aspect is that they do not change any properties of the mix besides viscosity. VMAs can be used alone, but are more commonly used with superplasticizers. In this combination, the superplasticizers take on the role of enhancing flow, while VMAs act to provide stability, while VMAs act to provide stability (Umar, Al-Tamimi 2011).

There are some discrepancies dealing with the effect of VMAs on the strength of SCC. The research results (Fu, Chung 1996; Khayat 1998; Rols et al. 1999; Lachemi et al. 2004a; Saric-Coric et al. 2003; Leemann, Winnfield 2007; Umar, Al-Tamimi 2011) suggest that VMA has a positive or negative compressive influence on strength of concrete. In the other works (Fu, Chung 1996; Saric-Coric et al. 2003) the negative effect of VMA was proved. Publication (Şahmaran et al. 2006) indicates that the influence of VMA on compressive strength depends on VMA and SP type.

The influence of type of AFA and VMA on porosity characteristic and frost-resistance of concrete was analyzed in the papers (Laźniewska-Piekarczyk 2011b, 2013). The research results proved that type of AFA and VMA significantly influence on porosity parameters of HPSCC.

The strength of concrete decreased with the increase in porosity. It is well known that strengths of Portland cement paste depend on porosity, pores size distribution, and pore shape (Odler, Robler 1985; Robler, Odler 1885). The strength of concrete is influenced by the volume of all voids in the concrete (entrapped air, capillary pores, gel pores and entrained air) (Kearsley, Wainwright 2002). The strength of cement mortar or paste is more heavily influenced by the volume and number of large size pores and mean pore diameter than by smaller pores (Robler, Odler 1885; Kearsley, Wainwright 2002). The research (Wee et al. 2011) results proved that the compressive strength of foamed concrete seems to be influenced by the spacing factor, $\mathrm{w} / \mathrm{c}$ ratio and air content in relation to density. The results also indicated that the inclusion of air-voids in foamed concrete had a greater effect on compressive strength than the modulus of elasticity and it increases with increase of $\mathrm{w} / \mathrm{c}$ ratio. The compressive strength of the foamed cement-fly ash concrete is highly correlated to the air-avoid structure factors (Yonghao et al. 2010). Do not know how chemical admixtures affect the strength-porosity relationship of the HPSCC. The research results indicated that AFA type significantly influence on compressive strength of mortar.

The article presents the development of HPSCC with different types of new generation SP: SP1 (with air entraining side effect) and SP2 (without entraining side effect) and different type new generation of AFA and VMA. The main objective of the research is to determine the influence the admixtures on the porosity and compressive strength of HPSCC. A study was then carried out on the fresh and hardened properties of different HPSCC at constant water on cement ratio, type and volume of aggregate, volume of cement paste.

\section{Materials and description of the tests}

\subsection{Examined materials}

A type CEM I 42.5 R cement and silica fume (SF) were used. Local natural sand, fine and eight-millimeter maximum size gravel aggregates, were used in concrete mix, respectively. The properties of admixtures are presented in

Tables 1-3 provide the chemical compositions of SPs, AFAs and VMAs are a proprietary commercial patent. 
Table 1. The properties of superplasticizers

\begin{tabular}{lcc}
\hline Property & $\mathrm{SP} 1$ & $\mathrm{SP} 2$ \\
\hline Main base & $\begin{array}{c}\text { polycarboxyl } \\
\text { ether }\end{array}$ & $\begin{array}{c}\text { polycarboxyl } \\
\text { ether }\end{array}$ \\
\hline $\begin{array}{l}\text { Specific Gravity at } 20{ }^{\circ} \mathrm{C}, \\
\mathrm{g} / \mathrm{cm}^{3}\end{array}$ & $1.07 \pm 0.02$ & $1.05 \pm 0.02$ \\
\hline $\mathrm{pH}$-value at $20{ }^{\circ} \mathrm{C}$ & $6.5 \pm 1.0$ & $6.5 \pm 1.5$ \\
\hline $\begin{array}{l}\text { Chloride ion content, } \% \\
\text { mas. }\end{array}$ & $\leq 0.1$ & 1.3 \\
\hline $\begin{array}{l}\text { Alkali content } \\
\text { (Na2Oeqiv.), \% mass }\end{array}$ & 1.5 & 1.3 \\
\hline
\end{tabular}

Table 2. The properties of anti-foaming admixtures

\begin{tabular}{ll}
\hline Symbol & \multicolumn{1}{c}{ Main base } \\
\hline AFA1 & polyalcohol \\
\hline AFA2 & $\begin{array}{l}\text { froth breaker on the PDMS basis/silicone oil/ } \\
\text { hydrophobic silica }\end{array}$ \\
\hline AFA3 & $\begin{array}{l}\text { froth breaker on the basis of alcohol derivative } \\
\text { of saturated fatty alcohol, mineral oil and PE } \\
\text { wax }\end{array}$ \\
\hline AFA4 & modified polyalcohol \\
\hline AFA5 & alkoxyl derivative of fatty alcohol, 100\% \\
\hline AFA6 & $\begin{array}{l}\text { froth breaker on the basis of mineral oil or } \\
\text { amidol wax }\end{array}$ \\
\hline
\end{tabular}

Table 3. The properties of viscosity modifying admixtures

\begin{tabular}{lccc}
\hline Property & VMA1 & VMA2 & VMA3 \\
\hline Main base & $\begin{array}{l}\text { synthetic } \\
\text { copolymer }\end{array}$ & silica & methylcellulose \\
\hline $\begin{array}{l}\text { Specific gravity at } \\
20^{\circ} \mathrm{C}, \mathrm{g} / \mathrm{cm}^{3}\end{array}$ & -1.02 & 1.30 & $*$ \\
\hline $\mathrm{pH}$-value at $20^{\circ} \mathrm{C}$ & $6-9$ & 9.5 & $*$ \\
\hline $\begin{array}{l}\text { Chloride ion content, } \\
\% \text { mas. }\end{array}$ & $<0.1$ & $*$ & $*$ \\
\hline $\begin{array}{l}\text { Alkali content } \\
\text { (Na2Oeqiv.), } \% \text { mass }\end{array}$ & $*$ & $*$ & $*$ \\
\hline
\end{tabular}

Note:*Data was not provided by the manufacturer.

\subsection{Mix proportion and its preparation}

Nineteen high performance self-compacting concrete mixtures (Tables 4-9) were made to study the effect of type of SP and AFA on the properties of HPSCC. The proportion of cement, silica fume, water, coarse aggregate and sand was kept constant (Table 4).

The following admixtures were used (Tables 5-8): SP1 (with air-entraining side effect), SP2 (without airentraining side effect), AFA1-AFA6 and VMA1-VMA3.

\subsection{Methodology of test of properties of HPSCC}

The tests of fresh high performance self-compacting concrete were carried out after $20 \mathrm{~min}$, because the SP liquefaction efficiency increases after time. Before the test concrete mixture was mixed for $5 \mathrm{~min}$.
Table 4. The components of HPSCC

\begin{tabular}{cccccc}
\hline $\begin{array}{l}\text { CEM I } \\
42,5 \mathrm{R}\end{array}$ & $\begin{array}{l}\text { Silica } \\
\text { fume }\end{array}$ & $\begin{array}{c}\text { Sand } \\
0 / 2 \mathrm{~mm}\end{array}$ & $\begin{array}{c}\text { Gravel } \\
0 / 8 \mathrm{~mm}\end{array}$ & \multirow{2}{*}{$\mathrm{w} / \mathrm{c}$} & $\mathrm{w} / \mathrm{b}$ \\
\cline { 1 - 4 } & \multicolumn{5}{c}{$\mathrm{kg} / \mathrm{m}^{3}$} \\
\hline 581.0 & 65.0 & 710.1 & 887.6 & 0.31 & 0.28 \\
\hline
\end{tabular}

Table 5. The dosage of SP by weight of total binder, $\%$

\begin{tabular}{lcc}
\hline Symbol & SP1 & SP2 \\
\hline H1 & 2.75 & - \\
\hline H2 & - & 4.34 \\
\hline
\end{tabular}

Table 6. The dosage of SP and AFA by weight of total binder, $\%$

\begin{tabular}{ccccccc}
\hline Symb. & SP1 & AFA1 & AFA3 & AFA4 & AFA5 & AFA6 \\
\hline H1A1 & 2.40 & 3.61 & & - & - & - \\
\hline H1A3 & 4.23 & - & 3.40 & - & - & - \\
\hline H1A4 & 3.67 & - & - & 3.48 & - & - \\
\hline H1A5 & 5.20 & - & - & - & 3.48 & - \\
\hline H1A6 & 3.67 & - & - & - & - & 4.06 \\
\hline
\end{tabular}

Table 7. The dosage of SP and VMA by weight of total binder, \%

\begin{tabular}{lccccc}
\hline Series & SP1 & SP2 & VMA1 & VMA2 & VMA3 \\
\hline H1V1 & 3.28 & - & 0.15 & - & - \\
\hline H1V2 & 3.67 & - & - & 0.25 & - \\
\hline H1V3 & 4.90 & - & - & - & 0.03 \\
\hline H2V1 & - & 4.92 & 0.58 & - & - \\
\hline H2V2 & - & 5.22 & - & 1.37 & - \\
\hline H2V3 & - & 5.05 & - & - & 0.07 \\
\hline
\end{tabular}

Table 8 . The dosage of SP and AFA by weight of total binder, $\%$

\begin{tabular}{lcccc}
\hline Symbol & SP1 & AFA1 & AFA2 & AFA3 \\
\hline H1A1V1 & 4.44 & 3.50 & - & - \\
\hline H1A2V1 & 3.67 & - & 3.45 & - \\
\hline H1A3V1 & 3.79 & - & - & 3.45 \\
\hline H1A3V2 & 3.67 & - & - & 3.45 \\
\hline H1A1V2 & 4.28 & 3.45 & - & - \\
\hline H1A1V3 & 4.95 & 4.07 & - & - \\
\hline
\end{tabular}

Table 9. The dosage of VMA by weight of total binder, $\%$

\begin{tabular}{lccc}
\hline Symbol & VMA1 & VMA2 & VMA3 \\
\hline H1A1V1 & 0.26 & - & - \\
\hline H1A2V1 & 0.25 & - & - \\
\hline H1A3V1 & 0.19 & - & - \\
\hline H1A3V2 & - & 0.25 & - \\
\hline H1A1V2 & - & 0.25 & - \\
\hline H1A1V3 & - & - & 0.11 \\
\hline
\end{tabular}


The main aim of this step of the research is to compress the influence of type of admixtures on workability and air volume of fresh HPSCC. The slump flow test (EN 12350-8:2010) (2010) was used to evaluate the free deformability and flowability of SCC. Slump flow value represented the mean diameter (measured in two perpendicular directions) of concrete after lifting the standard slump cone. The upper and lower limits of slump-flow classes (SF) are the following (EN 12350-8:2010): SF1 - slump flow from 50 to $650 \mathrm{~mm}, \mathrm{SF} 2$ - slump flow from 660 to $750 \mathrm{~mm}$, SF3 - slump flow from 760 to $850 \mathrm{~mm}$. While the upper and lower limits of viscosity classes (VS) are the following (EN 12350-8:2010): VS1 $-\mathrm{T}_{500}$ less than or equal to $2 \mathrm{sec} ., \mathrm{VS} 2-\mathrm{T}_{500}$ greater than $2 \mathrm{sec}$.

The air content in fresh HPSCC was measured by the pressure method according to EN 12350-7 (2009).

The temperature and relative humidity were respectively $20^{\circ} \mathrm{C}$ and $100 \%$ (in water). After 28 days, the tests were conducted to determine the air-voids parameters of HPSCC.

The entrained air void distribution in hardened concrete was determined using a computer-driven system of automatic image analysis. Tests were performed using polished concrete specimens $100 \times 100 \times 20 \mathrm{~mm}$ cut from cube specimens. The automatic measurement procedure was designed to comply with the requirements imposed by EN 480-11 (2005). Results of measurements were available as a set of standard parameters for air void microstructure characterization: spacing factor $(\mathrm{mm})$, specific surface $\alpha(1 / \mathrm{mm})$, air content A (\%), content of air voids with diameter less than $0.3 \mathrm{~mm} \mathrm{~A}_{300}(\%)$, air void diameters distribution.

Capillary porosity of HPSCC was estimated by the means of porosimeter. The pores with diameter from $3 \mathrm{~nm}$ to $250 \mathrm{~mm}$ were measured with pressure from $1 \mathrm{kPa}$ to $400 \mathrm{MPa}$. The measurement was carried out by a continuous method (scan mode). The changes of mercury volume were estimated during pressure increase and decrease.

The compressive strength of HPSCC was measured according to EN 12390-3:2011 (2011).

\section{Test results and its discussion}

\subsection{The research results of fresh HPSCC}

Test results of the test of properties of the fresh modified HPSCC by admixtures are summarized in Table 10. The analysis of these research results suggests that the type of the new generation SP influences essentially the aircontent in the fresh high performance self-compacting concrete. Nevertheless SP1 increases the air content in HPSCC but less than that shown by the results of normal SCC with higher w/c ratio (Rols et al. 1999). The research results (Łaźniewska-Piekarczyk, Szwabowski 2012a) showed that excessive air-entrainment in concrete is mostly generated by some high water range reducers decreasing surface tension of liquid phase in cement paste.
The comparison of test results in Table 5 and Table 10 show that the "air-entraining" SP1 is more effective in action. Nevertheless, the slump flow of HPSCC with "non air-entraining" SP2 is higher.

The research results of the workability and aircontent of HPSCC with different type of AFA are summarized in Table 10. The analysis of the results shows that the type of AFA is important both in terms of consistency and air content in HPSCC. The most beneficial effect in this regard is characterized by AFA4 based on modified polyalcohol. AFA4 causes the largest increase in diameter of the flow and reduce the air content in HPSCC. AFA6 (on the basis of mineral oil or amidol wax) has the least positive influence in this regard.

The effect of a VMA on rheology and setting time of concrete depends on the type and concentration of VMA, the type and dosage of SP, as well as on the cement composition and w/c (Khayat 1998). The study (Prakash, Santhanam 2006) investigated the interactions between a water soluble polysaccharide VMA and two types of SPs (one based on sulfonated naphthalene formaldehyde SNF - and the other on polycarboxylic ether - PCE technology) in an SCC system. The results indicated that while both types of SPs are compatible with the VMA used (welan gum), the pseudoplastic nature of the VMA and thixotropy of paste depends on the type of SP used.

The research results of the workability and aircontent of HPSCC with VMA1, VMA2 and VMA3 are summarized in Table 10. The analysis of the results indicates that VMA (regardless of the VMA type) influences the air content in fresh HPSCC. VMA2 and VMA3 result in the decrease of the air-content in HPSCC with SP1. A different situation is the case of VMA3. Adding VMA3 to the HPSCC with SP2, results in a significant increase in the air content in HPSCC due to the increase of plastic viscosity (increase in $\mathrm{T}_{500}$ ) and yield stress (decrease of SF). Moreover, a combination of the type of SP and VMA is important because of HPSCC workability. The workability of H1V2 and H2V1 is better than workability of $\mathrm{H} 1$ and $\mathrm{H} 2$. While, workability of H1V1 and $\mathrm{H} 2 \mathrm{~V} 2$ is similar to the workability of $\mathrm{H} 1$ and $\mathrm{H} 2$. The most beneficial to improve the workability is in case of HPSCC with SP2 and VMA3 (series H2V3). The most effective admixture is VMA3, and then respectively VMA1 and VMA2.

In Table 10 the research results of properties of HPSCC with AFA1, AFA2, AFA4 and VMA1, VMA2, VMA3 are summarized. The analysis of the results leads to the conclusion that the VMA causes various changes in HPSCC consistency, depending on both the AFA and VMA. The use of AFA3 with VMA2 is most suitable for workability and air content of HPSCC. The least favorable impact, as in case of $\mathrm{H} 2 \mathrm{~V} 3$, is characterized by VMA3. H1A1V3 has a $\mathrm{SF}$ of $500 \mathrm{~mm}$ and a $\mathrm{T}_{500}$ of 9 seconds and in Table 22 concrete H2A1V3 has a SF of $500 \mathrm{~mm}$ and a $\mathrm{T}_{500}$ of 10 seconds. These two last examples would not be classified as SCC. VMA3 (based on methylcellulose), increases the viscosity of nonair-entrained and air entrained SCC the most. VMA based 
Table 10. Properties of fresh HPSCC (Łaźniewska-Piekarczyk 2013)

\begin{tabular}{lccccc}
\hline Symbol & $\begin{array}{c}\mathrm{SF} \\
\mathrm{mm}\end{array}$ & $\begin{array}{c}\mathrm{T}_{500} \\
\text { sec. }\end{array}$ & $\begin{array}{c}\text { Slump-Flow } \\
\text { classes }\end{array}$ & $\begin{array}{c}\text { Viscosity } \\
\text { classes }\end{array}$ & $\begin{array}{c}\mathrm{A}_{\mathrm{c}} \\
\%\end{array}$ \\
\hline H1 & 660 & 6 & $\mathrm{SF} 2$ & $\mathrm{VS} 2$ & 3.5 \\
\hline H2 & 680 & 3 & $\mathrm{SF} 2$ & $\mathrm{VS} 2$ & 2.2 \\
\hline H1A1 & 690 & 3 & $\mathrm{SF} 2$ & $\mathrm{VS} 2$ & 2.5 \\
\hline H1A3 & 670 & 4 & $\mathrm{SF} 2$ & $\mathrm{VS} 2$ & 2.4 \\
\hline H1A4 & 850 & 2 & $\mathrm{SF} 3$ & $\mathrm{VS} 1$ & 2.0 \\
\hline H1A5 & 630 & 6 & $\mathrm{SF} 1$ & $\mathrm{VS} 2$ & 2.9 \\
\hline H1A6 & 600 & 3 & $\mathrm{SF} 1$ & $\mathrm{VS} 2$ & 2.9 \\
\hline H1V1 & 650 & 4 & $\mathrm{SF} 1$ & $\mathrm{VS} 2$ & 2.4 \\
\hline H2V1 & 730 & 3 & $\mathrm{SF} 2$ & $\mathrm{VS} 2$ & 1.8 \\
\hline H1V2 & 770 & 4 & $\mathrm{SF} 3$ & $\mathrm{VS} 2$ & 2.7 \\
\hline H2V2 & 640 & 4 & $\mathrm{SF} 1$ & $\mathrm{VS} 2$ & 1.9 \\
\hline H2V3 & 580 & 7 & $\mathrm{SF} 1$ & $\mathrm{VS} 2$ & 3.6 \\
\hline H1V3 & 680 & 8 & $\mathrm{SF} 2$ & $\mathrm{VS} 2$ & 2.6 \\
\hline H1A1V1 & 700 & 4 & $\mathrm{SF} 2$ & $\mathrm{VS} 2$ & 2.4 \\
\hline H1A2V1 & 650 & 5 & $\mathrm{SF} 1$ & $\mathrm{VS} 2$ & 3.9 \\
\hline H1A3V1 & 730 & 6 & $\mathrm{SF} 2$ & $\mathrm{VS} 2$ & 2.7 \\
\hline H1A3V2 & 790 & 4 & $\mathrm{SF} 3$ & $\mathrm{VS} 2$ & 1.2 \\
\hline H1A1V2 & 730 & 5 & $\mathrm{SF} 2$ & $\mathrm{VS} 2$ & 2.3 \\
\hline H1A1V3 & 500 & 9 & $\mathrm{SF} 1$ & $\mathrm{VS} 2$ & 4.9 \\
\hline & & & & & \\
\hline
\end{tabular}

on methylcellulose is not recommended to obtain good workability of HPSCC. Moreover, addition of VMA3 causes a significant increase of the air content in HPSCC.

\subsection{The research results of hardened HPSCC}

In Figures 1-3 the air voids parameters research results are presented. The research results proved that admixture type is very important to the values of the HPSCC airvoids parameters.

The analysis of the results summarized in Figures 1-3 lead to the conclusion that the type of SP is very important because of the parameters values of the HPSCC air voids.

The research results of the air voids characteristics of HPSCC with VMA1, VMA2 and VMA3 are summarized in Figures 1-3. The analysis of the results suggests that the type of VMA is very important due to the size of the air voids parameters of HPSCC. The type of SP is also important because of the influence of VMA in this regard. The use of VMA leads to the reduction of the air content in concrete according to research results (Saric-Coric et al. 2003; Lachemi et al. 2004a; Łaźniewska-Piekarczyk 2012). However, the research results in Figures 1-3 show that the parameters of the HPSCC air voids are characterized by very different values, depending on what type of SP and VMA was used.

Comparing the porosity parameters of HPSCC with SP1 and the different types of VMA (H1V1, H1V2 and

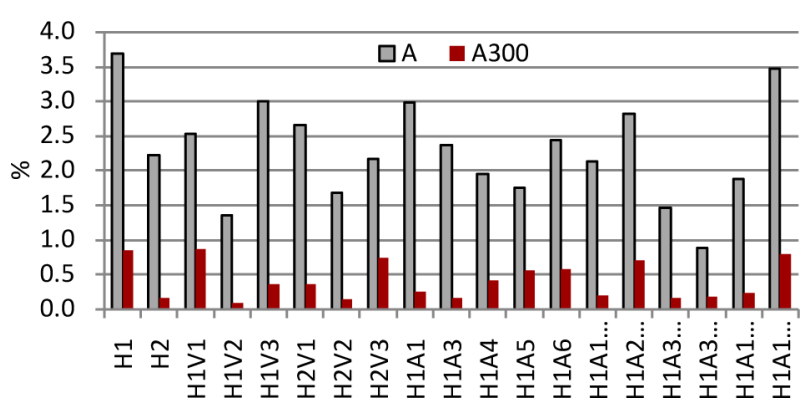

Fig. 1. The air-void volume of HPSCC (ŁaźniewskaPiekarczyk 2013)

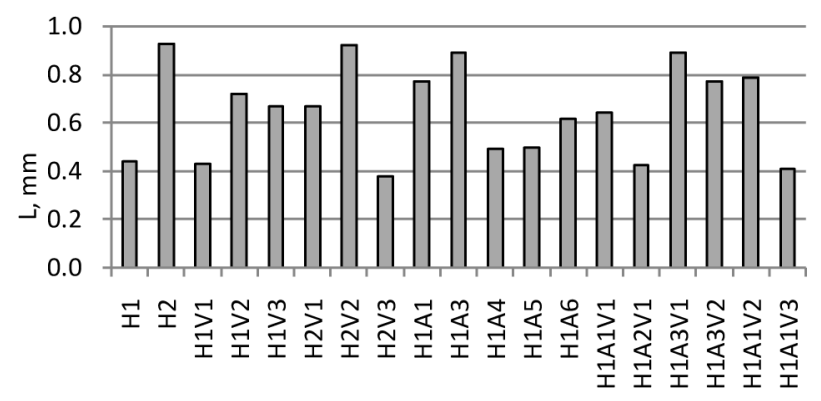

Fig. 2. The air-void spacing factor of HPSCC (ŁaźniewskaPiekarczyk 2013)

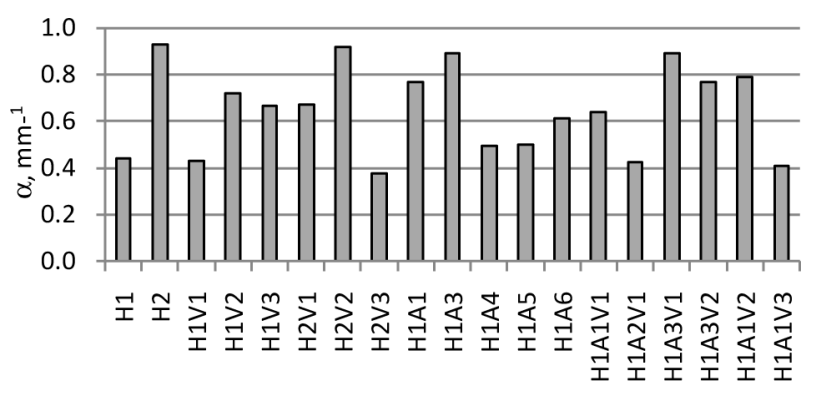

Fig. 3. The air-void specific surface of HPSCC (ŁaźniewskaPiekarczyk 2013)

H1V3), it appears that the VMA2 causes the greatest reduction in the air content in HPSCC. VMA2 increases the size of the air voids spacing factor and decreases the content of voids smaller than $300 \mathrm{~mm}$. VMA1 (based on synthetic copolymer) does not cause significant changes in parameters of the air voids, in addition to the total of their contents. VMA3 (based on methylcellulose) does not cause a significant reduction in the air content of HPSCC. However, the research results summarized in Figure 3 show that the pores are characterized by larger diameters (compare $\mathrm{H} 1$ and $\mathrm{H} 1 \mathrm{~V} 3$ ).

The addition of VMA to HPSCC with SP2 also changes the parameters of the air voids size, smaller or larger, depending on the type of VMA. VMA3 (based on methylcellulose) causes the greatest change in pore size (Fig. 3). Furthermore, the air voids spacing factor is reduced almost three times. The specific surface of the voids is reduced more than doubled (compare $\mathrm{H} 2$ and $\mathrm{H} 2 \mathrm{~V} 3$ ). The greatest reduction in porosity causes VMA2 (based on silica), as in case of HPSCC with SP1. 
The research results of the air-voids characteristics of HPSCC with AFA1-AFA6 are shown in Figures 1-3. The analysis of the results proves that the type of AFA is important because of the value of the parameters of the air voids in HPSCC. The most effective admixture in reducing the air content in HPSCC is AFA5, and the least efficient, AFA1. The greatest increase in the air voids diameters is in case of HPSCC with AFA3.

Figures 1-3 show the research results of HPSCC porosity characteristics with AFA1, AFA2, AFA3 and VMA1, VMA2, VMA3. The analysis of the results suggests that the type of AFA and VMA is important because of the porosity of HPSCC. VMA1 and VMA2 decrease the air voids content in HPSCC with AFA1, whereas VMA3 increases the air voids content. VMA2 causes greater reduction in porosity than VMA1 in case of HPSCC with AFA3.

In data in Figure 4 the porosity characteristics according to mercury intrusion method (MIP) of HPSCC are presented. The following parameters have been identified: specific surface $\left(\mathrm{S}_{\mathrm{w}}\right)$ and total volume of pores (V). The analysis of the results shows that the type of SP and VMA is very important because of the characteristics open porosity of HPSCC. The mercury intrusion porosimetry test (Valcuende et al. 2012) results showed that the use of viscosity-modifying admixture on SCC does not affect the total volume of pores but generates a slightly coarser porous microstructure.

The content of the pores in the HPSCC with SP1 is almost three times higher than in case of HPSCC with SP2. Depending on the type of VMA, is a reduction or an increase in the porosity of HPSCC. VMA2 reduces the content of pores in HPSCC with SP1 most. VMA3 increases the content pores in HPSCC with SP1 most.

The research results of compressive strength of HPSCC are summarized in Figure 5. Analyze of the lead to the conclusion that the type of admixture is very important because of the strength of HPSCC.

Compressive strength can be interpreted as a function of the total porosity, or void content, in hardened concrete. Total porosity is the air volume (air content) plus the capillary porosity (Pinto, Hover 2001). These

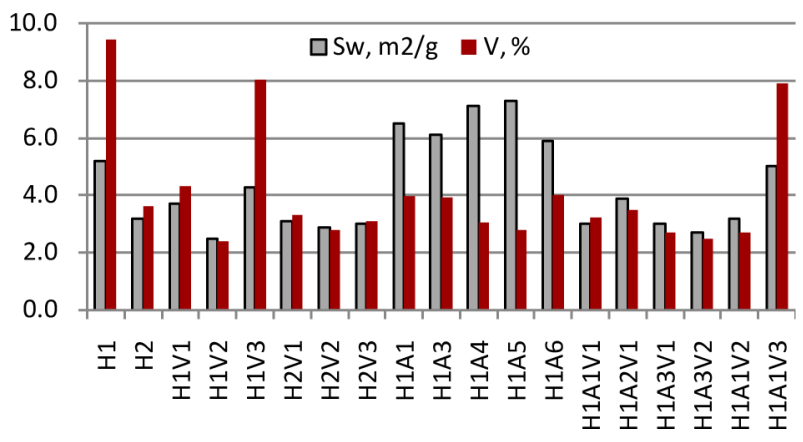

Fig. 4. The research results of open porosity of HPSCC by the mercury intrusion method (MIP)

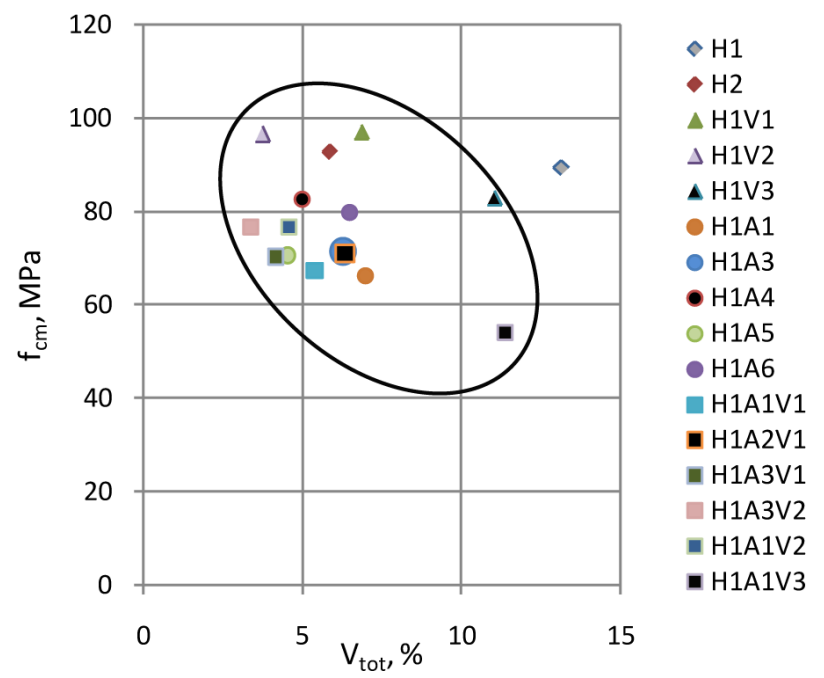

Fig. 5. The comparison of the research results of compressive strength and total porosity of HPSCC

research results proved that a consistent linear relationship between total porosity (based on the Powers model) and compressive strength was obtained for all mixtures. The analysis of results presented in Figure 5 suggests that the type of admixture and its combinations disturb the relationship between the strength and total pore content $\left(\mathrm{V}_{\text {tot }}\right)$ of HPSCC. The compressive.

In case of AFA4 (based on modified polyalcohol) the compressive strength of HPSCC is the highest. Total porosity of AFA5 modified HPSCC is similar to total porosity AFA4 modified HPSCC, but strength these concretes is different. AFA1 (based on polyalcohol) most negatively affects the strength of the concrete due to the least efficient in reducing the amount of air-voids (Fig. 1).

Many studies have been carried out on the fluidizing mechanisms of these admixtures in cement paste, and some theories have been used to explain the mechanisms by which these admixtures interact with cement particles, such as the DLVO Theory, the Steric Effect Theory, the Depletion Effect Theory and the Tribology Effect (Ohta et al. 1997; Ghezal 2003). However, when systems contain blended ternary cement in the presence of SP combined with VMA like the most formulations of SCC, it becomes more difficult to predict the evolution of the systems and to explain the mechanisms of the resulting interactions.

When a VMA is used in a low w/c systems (for example 0.30), it may interfere with degree of cement hydration and reduce the rate of strength development (Khayat 1996). However, when used in mixtures that necessitate the incorporation of a VMA to enhance stability (w/c > 0.40), the VMA does not seem to have a significant effect on strength development. Owing to the increase in stability, the resulting cohesive concrete can develop a denser transition zone between the cement paste and aggregate that can enhance bond strength to embedded reinforcement and impermeability. This can 
also results in a greater flexural-to-compressive strength ratio compared with non-VMA concrete of similar consistency (Khayat 1996). These research results showed that non-air-entrained concrete made with w/c ratios of $0.60,0.45$ and 0.30 containing a VMA had 1 to $2.3 \%$ higher air content in hardened state than non-VMA mixtures, which may result in 5 to $10 \%$ compressive strength reduction. The mixtures made with welan gum and $0.30 \mathrm{w} / \mathrm{c}$ exhibited up to $10 \%$ drop in compressive strength. Such a reduction was $15 \%$ in concrete made with HPMC and $0.60 \mathrm{w} / \mathrm{c}$ and $20 \pm 10 \%$ for HPMC concrete with $\mathrm{w} / \mathrm{c}$ ratios of 0.45 to 0.30 . The research results (Khayat 1998) the effect of type and concentration of VMA on the compressive strength of non-air entrained concrete made with $0.41 \mathrm{w} / \mathrm{c}$ shoved that welan gum and liquid based cellulose do not cause significant decrease in strength (from $94 \pm 9 \%$ to $100 \pm 4 \%$ ). On the other hand, Leemann and Winnefeld (2007) proved that compressive strength at an age of 28 days is not affected by the use of VMA. These research results showed the effects of type of VMA on early cement hydration and compressive strength of concrete. It was proved that the organic VMA show almost no influence on early cement hydration and the development of compressive strength at an age of 28. However, the inorganic VMA cause an acceleration of hydration and higher compressive strength at the age of 1 day. The inorganic silica-based VMA accelerate early cement hydration with respect to the use of SP alone as determined by isothermal heat flow calorimetry. As a result, concrete compressive strength at the age of 1 day increases. The organic VMA show no obvious influence on early cement hydration. Research results (Khayat 1996) proved that despite the similar in compressive strengths of the VMA and non-VMA mixtures for any given w/c, concretes incorporating a VMA tested up to $40 \%$ lower rapid chloride-ion permeability values than corresponding non-VEA. All mixtures had similar slump values and hardened air content. The reduction in rapid chlorideion permeability was especially significant in the case of concrete made with $0.32 \mathrm{w} / \mathrm{c}$ incorporating HPMC. Such a reduction could be attributed mainly to the improvement of concrete homogeneity and reduction in the porosity of the transition zone between the bulk cement paste and aggregate (Khayat 1998).

In the publications (Fu, Chung 1996; Leemann, Winnfield 2007; Łaźniewska-Piekarczyk 2011a) the negative effect of VMA (based on methylcellulose) was proved. Analysis of the results suggests that VMA3 (based on methylcellulose) most decreases the compressive strength of HPSCC with SP1 (H1V3). VMA3 in case of HPSCC with SP1 causes an increase in the air content in its volume. VMA2 (based on silica) has the opposite effect to VMA3 effect due to the compressive strength of HPSCC. In case of HPSCC with VMA2 also obtained the smallest content of the air pores. However, the highest strength is characterized by HPSCC with VMA1 (based on synthetic copolymer), despite the considerable content of the air pores. On the other hand, in case of HPSCC with SP2 the use of VMA1 causes decrease of compressive strength. VMA2 (based on silica) has a positive influence on the strength in each case of HPSCC.

According to Şahmaran et al. (2006) the effect of viscosity modifying agents depends not only on the type of this admixture but also on the type of superplasticizer. When compared to the control mixture, the use of SPs generally increased the strength. Such an increase was not expected as the w/p was kept constant. However, similar observations were also made by other researchers (Lachemi et al. 2004a, 2004b) and the increase in strength was attributed to a better distribution of the cement grains in the mortar matrix when flow properties were increased (Neville 2011). The use of VMA (except methylcellulose) can increase the compressive strength of the HPSCC with "air-entraining" SP (compare H1 and H1V1 and H1V2). In case of HPSCC with non-airentraining SP the use of VMA does not increase its compressive strength. Moreover, VMA1 and VMA3 decrease of the compressive strength of HPSCC. The capillary pore volume of $\mathrm{H} 2$ and $\mathrm{H} 2 \mathrm{~V} 1$ is similar, but the compressive strength values of the $\mathrm{H} 2$ and $\mathrm{H} 2 \mathrm{~V} 1$ are no similar. VMA2 (based on silica) has a positive influence on the strength of H2. The HPSCC with SP2 and VMA2 has the smallest content of air-voids.

The research results (Christianto 2004) proved that the SP (a Polycarboxylate Eter based SP) increases the strength except for SP (based on Melamine Formaldehyde). Such an increase was not expected as the w/c ratio was kept constant. However, similar observations were also made by other researchers (Neville 2011), and the increase in strength was attributed to a better distribution of the cement grains in the mortar matrix when chemical admixtures were used. Moreover, the research results (Christianto 2004) showed that the SP-VMA combinations increased the strength of self-compacting mortars (SCMs). The VMAs (VMA based on an aqueous dispersion of microscopic silica and the other one based on high molecular weight hydroxylated polymer) did not affect the strength properties of the SCMs when used with SP, a Polycarboxylate Eter based SP. The same conclusion will not hold for the SP as the strength of the SP mixes when used with of the VMAs (Aqueous Dispersion of Microscopic Silica and High Molecular Weight Hydroxylated Polymer based VMAs) decreased considerably.

\section{Conclusions}

In the range of investigation of the HPSCC, used admixtures and received research results it was indicated that:

- The types of anti-foaming admixtures, viscosity modifying admixtures and its combinations significantly affect the porosity and the compressive strength of HPSCC. Total porosity is the air volume (air content) plus the capillary porosity. The type 
of admixture and its combinations disturb the relationship between the strength and total pore content of HPSCC.

- The most effective admixture in reducing the air voids content in HPSCC is the anti-foaming admixture based on alkoxyl derivative of fatty alcohol, and the least efficient, the anti-foaming admixture based on polyalcohol.

- In case of anti-foaming admixture based on modified polyalcohol the compressive strength of HPSCC is the highest. The anti-foaming admixture based on polyalcohol most negatively affects the strength of the HPSCC due to the least efficient in reducing the amount of air-voids.

- Synthetic copolymer and silica based viscosity modifying admixture result in the decrease of the air-content in HPSCC. Adding methylcellulose based viscosity modifying admixture to the HPSCC results in a significant increase in the air content in HPSCC.

- Viscosity modifying admixture based on silica has positive effect due to the compressive strength of HPSCC. Viscosity modifying admixture based on synthetic copolymer causes variable effect in this regard depending on the superplasticizers type. Viscosity modifying admixture based on methylcellulose most decreases the compressive strength of HPSCC.

\section{References}

Christianto, H. A. 2004. Effect of chemical and mineral admixtures on the fresh properties of self compacting mortars: Thesis. Graduate School of Natural And Applied Sciences of Middle East Technical University. 77 p.

EN 12350-8:2010 Testing fresh concrete. Self-compacting concrete. Slump-flow test. European standards. 2010.

EN 12350-7:2009. Testing fresh concrete. Air content. Pressure methods. European standards. 2009.

EN 480-11:2005. Admixtures for concrete, mortar and grout. Test methods. Determination of air void characteristics in hardened concrete. European standards. 2005.

EN 12390-3:2011. Testing hardened concrete. Compressive strength of test specimens. European standards. 2011.

Fang, Y.; Wang, R.; Pang, E.; Zhou, Y. 2010. Relationship between compressive strength and air-void structure of foamed cement-fly ash concrete, Journal of the Chinese Ceramic Society 38(4): 621-626.

Fu, X.; Chung, D. D. L. 1996. Effect of methylcellulose on the mechanical properties of cement, Cement and Concrete Research 26(4): 535-538. http://dx.doi.org/10.1016/0008-8846(96)00028-2

Ghezal, A. 2003. The effects of HRWRA-VMA combinations on fresh behavior of concrete equivalent mortar based on blended cement, in $3^{\text {rd }}$ International Symposium on SelfCompacting Concrete, 17-20 August 2003, Reykjavik, Iceland, 122-128.

http://dx.doi.org/10.1016/j.conbuildmat.2012.04.070

Gołaszewski, J. 2012. Influence of cement properties on new generation superplasticizers performance, Construction and Building Materials 35: 586-596.

Gorzelańczyk, T. 2012. Acoustically assessed influence of air pore structure on failure of self-compacting concretes under compression, Journal of Civil Engineering and Management 18(1): 60-70.

http://dx.doi.org/10.3846/13923730.2011.652982

Gorzelańczyk, T.; Hoła, J. 2011. Pore structure of selfcompacting concretes made using different superplasticizers, Archives of Civil and Mechanical Engineering 11(3): 611621. http://dx.doi.org/10.1016/S1644-9665(12)60104-6

Guidelines for Viscosity Modifying Admixtures for Concrete. 2006. In co-operation with EFCA The European Federation of Concrete Admixture Associations.

Kearsley, E. P.; Wainwright, P. J. 2002. The effect of porosity on the strength of foamed concrete, Cement and Concrete Research 32: 233-239. http://dx.doi.org/10.1016/S0008-8846(01)00665-2

Khayat, K. H. 1996. Effects of anti-washout admixtures on properties of hardened concrete, ACI Materials Journal 93(2): 134-146.

Khayat, K. H. 1998. Viscosity-enhancing admixtures for cement-based materials - an overview, Cement Concrete Composites 20(2-3): 171-188.

Khayat, K. H.; Guizani, Z. 1997. Use of viscosity modifying admixture to enhance stability of fluid concrete, $A C I M a-$ terials Journal 94(4): 332-340.

Lachemi, M.; Hossain, K. M. A.; Lambros, V.; Bouzoubaâ, N. 2003. Development of cost-effective self-consolidating concrete incorporating fly ash, slag cement, or viscosity-modifying admixtures, ACI Materials Journal 100(5): 419-425.

Lachemi, M.; Hossain, K. M. A.; Lambros, V.; Nkinamubanzi, P.-C.; Bouzoubaâ, N. 2004a. Selfconsolidating concrete incorporating new viscosity modifying admixtures, Cement and Concrete Research 34: 917-926.

Lachemi, M.; Hossain, K. M. A.; Lambros, V.; Nkinamubanzi, P.-C.; Bouzoubaâ, N. 2004b. Performance of new viscosity modifying admixtures in enhancing the rheological properties of cement paste, Cement Concrete Research 34(2): 185-193. http://dx.doi.org/10.1016/S0008-8846(03)00233-3

Łaźniewska-Piekarczyk, B. 2009. The effect of superplasticizers and anti-foaming agents on the air entrainment and properties of the mix of self compacting concrete, $\mathrm{Ce}$ ment, Wapno, Beton 29(3): 133-147.

Łaźniewska-Piekarczyk, B. 2010. Influence of anti-foaming admixture and polycarboxylic superplasticizer type on fresh and hardened properties of self-compacting mortar, Architecture Civil Engineering Environment 3(4): 61-72.

Łaźniewska-Piekarczyk, B. 2011a. Effect of viscosity stabilizing agents on the properties of self-compacting mortars and concretes, Cement Wapno Beton 1: 44 p.

Łaźniewska-Piekarczyk, B. 2011b. The influence of anti-foaming admixture on frost resistance and porosity characteristic of self-compacting concrete, Archives of Civil Engineering 57(4): 389-399. http://dx.doi.org/10.2478/v.10169-011-0028-y

Łaźniewska-Piekarczyk, B. 2012. The influence of selected new generation admixtures on the workability, air-voids parameters and frost-resistance of Self Compacting Concrete, Construction and Building Materials 31: 310-319. http://dx.doi.org/10.1016/j.conbuildmat.2011.12.107

Łaźniewska-Piekarczyk, B. 2013. The influence of admixtures type on the air-voids parameters of non-air-entrained and air-entrained high performance SCC, Construction and Building Materials 41: 109-124. http://dx.doi.org/10.1016/j.conbuildmat.2012.11.086

Łaźniewska-Piekarczyk, B.; Szwabowski, J. 2012a. Anti-foaming admixture (AFA) and its influences on the properties of a fresh self-compacting concrete mix, Journal of Civil Engineering and Management 18(2): 151-157. http://dx.doi.org/10.3846/13923730.2012.657410 
Łaźniewska-Piekarczyk, B.; Szwabowski, J. 2012b. The influence of the type of anti-foaming admixture and superplasticizer on the properties of self-compacting mortar and concrete, Journal of Civil Engineerng and Management 18(3): 408-415.

http://dx.doi.org/10.3846/13923730.2012.698908

Leemann, A.; Winnfield, F. 2007. The effect of viscosity modifying agents on mortar and concrete, Cement \& Concrete Composites 29: 341-349. http://dx.doi.org/10.1016/j.cemconcomp.2007.01.004

Lowke, D.; Wiegrink, K.; Schiessl, P. 2003. A simple and significant segregation test for SCC, in O. Wallevik, I. Nielsson (Eds.). Proceedings of the $3^{\text {rd }}$ International RILEM Symposium on Self-Compacting Concrete, RILEM Publications S.A.R.L., 2003, Reykjavik, 358-366.

MacInnis, C.; Racic, D. 1986. The effect of superplasticizers on the entrained air-void system in concrete, Cement and Concrete Research 16(3): 345-352.

Nagataki, S.; Fujiwara, H. 1995. Self compacting property of highly flowable concrete, in The Second CANMET/ACI International Symposium on Advances in Concrete Technology, June 1995, Las Vegas, USA, SP-154, 301-314.

Neville, A. M. 2011. Properties of concrete. 5 ed. Prentice Hall. $872 \mathrm{p}$.

Odler, I.; Robler, M. 1985. Investigation on the relationship between porosity, structure and strength of hydrated Portland cement paste. (II) Effect of pore structure and of degree of hydration, Cement Concrete Research 15: 401-410. http://dx.doi.org/10.1016/0008-8846(85)90113-9

Ohta, A.; Sugiyama, T.; Tanaka Y. 1997. Fluidizing mechanism and application of polycarboxylate-based superplasticizers, in $5^{\text {th }} C A N M E T / A C I$ International Conference on Superplasticizers and Other Chemical Admixtures in Concrete, 1997, American Concrete Institute, Farmington Hills, SP-173-19: 359-378.

Pinto, R. C. A.; Hover, K. C. 2001. Frost and scaling resistance of high-strength concrete, RD122. Skokie, Illinois: Portland Cement Association. 75 p.

Ponikiewski, T.; Gołaszewski, J. 2012. The self-compacting properties of concrete mixture of cement with calcareous fly ash addition, Cement Wapno Beton 17(4): 233.

Ponikiewski, T. 2012. The rheological and mechanical properties of steel fibres reinforced self compacting concrete, Cement Wapno Beton 17(5): 301 p.

Prakash, N.; Santhanam, M. 2006. A study of the interaction between viscosity modifying agent and high range water reducer in self compacting concrete, Measuring, Monitoring and Modeling Concrete Properties, Part 5: 449-454.
Robler, M.; Odler, I. 1885. Investigation on the relationship between porosity, structure and strength of hydrated Portland cement pastes. (1) Effect of porosity, Cement Concrete Research 15: 320-330. http://dx.doi.org/10.1016/0008-8846(85)90044-4

Rols, S.; Ambroise, J.; Péra, J. 1999. Effects of different viscosity agents on the properties of self-leveling concrete, Cement and Concrete Research 29: 261-266

Şahmaran, M.; Christianto, H. A.; Yaman, İ. Ö. 2006. Effect of chemical and mineral admixtures on the fresh properties of self-compacting mortars, Cement and Concrete Composites 28(5): $432-440$. http://dx.doi.org/10.1016/j.cemconcomp.2005.12.003

Sari, M.; Prat, E.; Labastire, J.-F. 1999. High strength self-compacting concrete: original solutions associating organic and inorganic admixtures, Cement Concrete Research 29(6): 813-818. http://dx.doi.org/10.1016/S0008-8846(99)00037-X

Saric-Coric, M.; Khayat, K. H.; Tagnit-Hamou, A. 2003. Performance characteristics of cement grouts made with various combinations of high-range water reducer and cellulose-based viscosity modifier, Cement and Concrete Research 33: 1999-2008.

Szwabowski, J.; Łaźniewska-Piekarczyk, B. 2008. The increase of air-content in mix under influence of carboxylate superplasticizers acting, Cement Wapno Beton 4: 205-215.

Szwabowski, J.; Łaźniewska-Piekarczyk, B. 2009. Airentrainment problem in self-compacting concrete, Journal of Civil Engineering and Management 15(2): 137-147. http://dx.doi.org/10.3846/1392-3730.2009.15.137-147

Umar, A.; Al-Tamimi, A. 2011. Influence of Viscosity Modifying Admixture (VMA) on the properties of SCC produced using locally supplied materials in Bahrain, Jordan Journal of Civil Engineering 5(1): 32-49.

Valcuende, M.; Parra, C.; Marco, E.; Garrido, A.; Martínez, E.; Cánoves, J. 2012. Influence of limestone filler and viscosity-modifying admixture on the porous structure of self-compacting concrete, Construction and Building Materials 28: 122-128. http://dx.doi.org/10.1016/j.conbuildmat.2011.07.029

Wee, T.-H.; Daneti, S. B.; Tamilselvan, T. 2011. Effect of w/c ratio on air-void system of foamed concrete and their influence on mechanical properties, Magazine of Concrete Research 63(8): 583-595. http://dx.doi.org/10.1680/macr.2011.63.8.583

Whiting, D.; Dziedzic, D. 1992. Effects of conventional and high-range water reducers on concrete, Properties, Research and Development Bulletin RD107. Portland Cement Association. 25 p.

Beata LAŹNIEWSKA-PIEKARCZYK. Reader of Engineering in the Department of Civil Engineering at the Silesian University of Technology in Gliwice, Poland. Her research interests include the technology of self-compacting concretes, high and very high-performance self-compacting concretes (HPSCC and VHPSCC); the formation of workability, resistance and durability of self-compacting concretes containing various chemical admixtures (fluxing and stabilizing - VMA - viscosity modifying admixture), air-entraining and anti-foaming admixtures and also mineral additives; the problems concerning the characteristic of porosity structures of the concretes containing various chemical and mineral additives used in technology of concretes and their influence on the mechanic parameters and resistance of the concrete. 